\title{
Water Depth Inversion in Haikou Bay Based on TM Image
}

\author{
Kun Ruan \\ Key Laboratory of Virtual Geographic Environment of \\ Ministry of Education \\ College of Geographic Science \\ Nanjing Normal University \\ Nanjing, China \\ Xiaodong Zhang \\ College of Harbor Coastal and Offshore Engineering \\ Hohai University \\ Nanjing, China
}

\author{
Shouxian Zhu* \\ College of Harbor Coastal and Offshore Engineering \\ Hohai University \\ Nanjing, China \\ Corresponding author: zhushouxian@vip.sina.com
}

\author{
Wenhua Zeng \\ Institute of Meteorology and Marine, \\ PLA University of Science and Technology \\ Nanjing, China
}

\begin{abstract}
Remote sensing has been proved to be a useful technique in measuring water depth in coastal zone. This paper takes Haikou Bay as the study area. The spectral analysis of the correlation index between TM image and the observed water depth from chart is made. TM3 gives the largest absolute correlation index in the all single spectra, and TM1/TM3 gives the larger absolute correlation index than other band ratios. Then some models using linear, logarithmic, power exponential and exponential equations have been made for water depth inversion, in which TM3, TM1/TM3 have been used. The exponential model based on the ratio of TM1 and TM3 is proved to be the best one.
\end{abstract}

Index Terms-Water depth inversion, Remote sensing, TM, Haikou Bay.

\section{INTRODUCTION}

The water depth of coast is very important for shipping, harbor construction, aquaculture, laying cable pipelines and military. The traditional method uses sounding instruments on the vessel, which is high cost and low efficiency. Remote sensing technology is also used in water depth inversion recently, which is widely coverage, convenient and economic $[1][2]$

The visible light has good ability to penetrate water. The light radiation intensity transmitting to the water is gradually weakened because of the absorption and reflection effect of the water. So the water depth can be derived from the visible radiation intensity received by satellite ${ }^{[3,4]}$. However, the remote sensing visible spectra are also affected by other factors such as sediment composition, water quality and atmospheric conditions $^{[5]}$.

Some researchers have extracted water depth from multispectral remote sensing data since the launch of the first Landsat satellite in 1972. Jerlov has carried out depth inversion study using a single-band model, in which the seabed reflection and water decay coefficient were taken as uniform in the study area ${ }^{[6]}$. Poleyn and Sattinger proposed the band ratio method to eliminate the influence of varied seabed reflection and decay coefficient of the water ${ }^{[7]}$. Paredes and Spero studied water depth inversion using multi-band method for many types of seabed sediment ${ }^{[8]}$. The purpose of this paper is to make depth inversion in Haikou Bay on TM image from Landsat satellite.

\section{THE STUDY AREA AND DATA}

The study area is $110^{\circ} 11^{\prime} 30^{\prime \prime} \mathrm{E} \sim 110^{\circ} 22^{\prime} 30^{\prime \prime} \mathrm{E}$ and $20^{\circ} 1{ }^{\prime} \mathrm{N} \sim 20^{\circ} 06^{\prime} \mathrm{N}$. The observed depth data for depth inversion is from the underwater topographic map of Haikou Bay published in 2003. The study area is shown in figure 1, and there are 1039 sample points of observed depth data in the study area.

Remote sensing data is selected from a Landsat-5 satellite image, it is on March 16, 2007. The remote sensing image is shown in Figure 2, which is processed by radiometric calibration operation and dark subtraction.

\section{SPECTRAL ANALYSIS}

There are six bands in TM visible light infrared group. Two of them are short-wave infrared bands, which have bad ability to penetrate water. So we only analyze the correlation between the other four bands and the observed depth. The correlation equation is

$$
r=\frac{\sum_{i=1}^{N}\left(x_{i}-\bar{x}\right)\left(y_{i}-\bar{y}\right)}{\sqrt{\sum_{i=1}^{N}\left(x_{i}-\bar{x}\right)^{2}} \sqrt{\sum_{i=1}^{N}\left(y_{i}-\bar{y}\right)^{2}}}
$$

$\mathrm{r}$ is the correlation index, $x_{i}$ is the reflectance factor, $\bar{x}$ is the average of the reflectance factor, $y_{i}$ is water depth, $\bar{y}$ is the 
average of water depth, $\mathrm{N}$ is the number of samples. The correlation index of reflectivity factor and depth value is shown in Table I. In the four single bands, namely TM1, TM2, TM3 and TM4, TM3 has the best correlation with the observed water depth data. TM1/TM3 gives the larger correlation index than other ratios of two spectra such as TM1/TM2, TM1/TM4, TM2/TM3, TM2/TM4 and TM3/TM4.

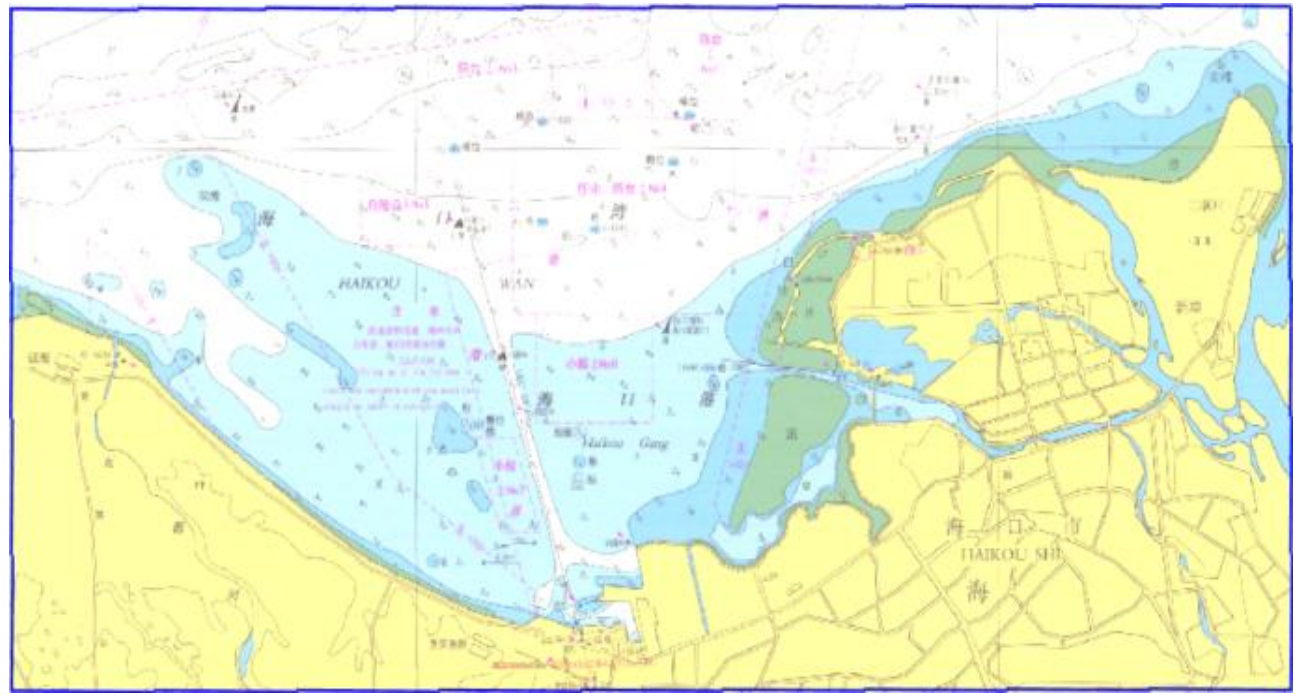

Fig. 1. The study area

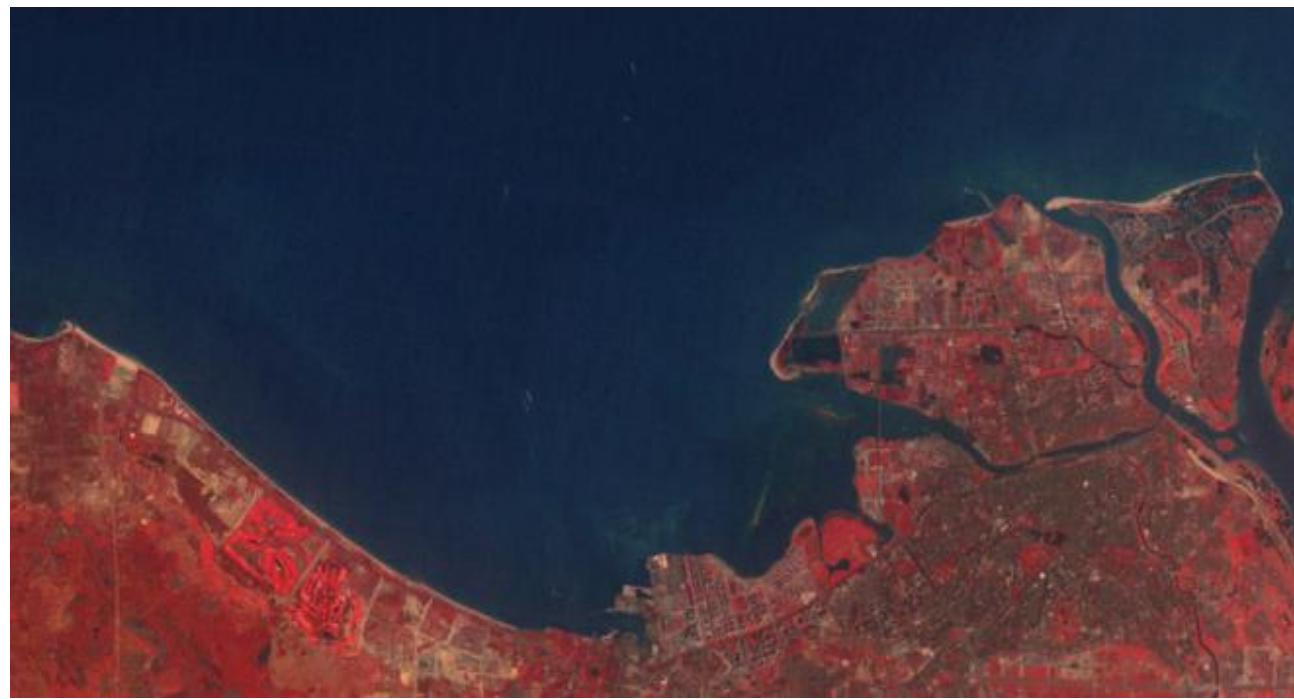

Fig. 2. The remote sensing image

TABLE I. THE CORRELATION INDEX OF THE SENSING REFLECTANCE FACTOR AND THE OBSERVED WATER DEPTH

\begin{tabular}{|c|c|c|c|c|c|c|c|c|c|c|}
\hline $\mathbf{x}$ & TM1 & TM2 & TM3 & TM4 & TM1/TM2 & TM1/TM3 & TM1/TM4 & TM2/TM3 & TM2/TM4 & TM3/TM4 \\
\hline $\mathbf{r}$ & 0.139 & -0.347 & & & & 0.625 & 0.608 & 0.610 & 0.592 & 0.369 \\
\hline $\begin{array}{l}\mathrm{Th} \\
\text { found } \\
\text { power } \\
\text { are ch }\end{array}$ & $\begin{array}{l}\text { IV. RE } \\
\text { lectanc } \\
\text { er dept } \\
\text { onentia } \\
\text { d by th }\end{array}$ & OF V & DEP & $1 \mathrm{ado}$ & $\begin{array}{l}\text { ected to } \\
\text { rithmic, } \\
\text { models }\end{array}$ & \multicolumn{5}{|c|}{$\begin{array}{l}\text { average relative error is } 0.362 \text {. The best model using } \\
\text { TM1/TM3 is with exponential equation, its average relative } \\
\text { error is } 0.343 \text {. Figure } 3 \text { gives the result of depth inversion with } \\
\text { exponential equation of TM1/TM3. The inversed depth } \\
\text { becomes shallow to shore, which accords with the main actual } \\
\text { character. }\end{array}$} \\
\hline
\end{tabular}

model using TM3 is with power exponential equation, its 
TABLE II. THE CHECK OF THE DEPTH INVERSION MODELS

\begin{tabular}{|c|c|c|c|}
\hline $\begin{array}{c}\text { Reflectance } \\
\text { factor }(\mathbf{x})\end{array}$ & Model type & Equation & Mean relative error \\
\hline \multirow{4}{*}{ TM3 } & Linear & $y=-854.9499 x+37.331$ & 0.464 \\
\cline { 2 - 4 } & Logarithmic & $y=-30.505 \ln x-95.761$ & 0.441 \\
\cline { 2 - 4 } & Power exponential & $y=3.412 \times 10^{-3} x^{-2.264}$ & 0.362 \\
\cline { 2 - 4 } & Exponential & $y=69.303 e^{-64.829 x}$ & 0.395 \\
\hline & Linear & $y=5.750 x-20.669$ & 0.411 \\
\cline { 2 - 4 } & Logarithmic & $y=29.807 \ln x-39.394$ & 0.435 \\
\cline { 2 - 4 } & Power exponential & $y=0.217 x^{2.231}$ & 0.359 \\
\cline { 2 - 4 } & Exponential & $y=0.917 e^{0.423 x}$ & 0.343 \\
\hline
\end{tabular}

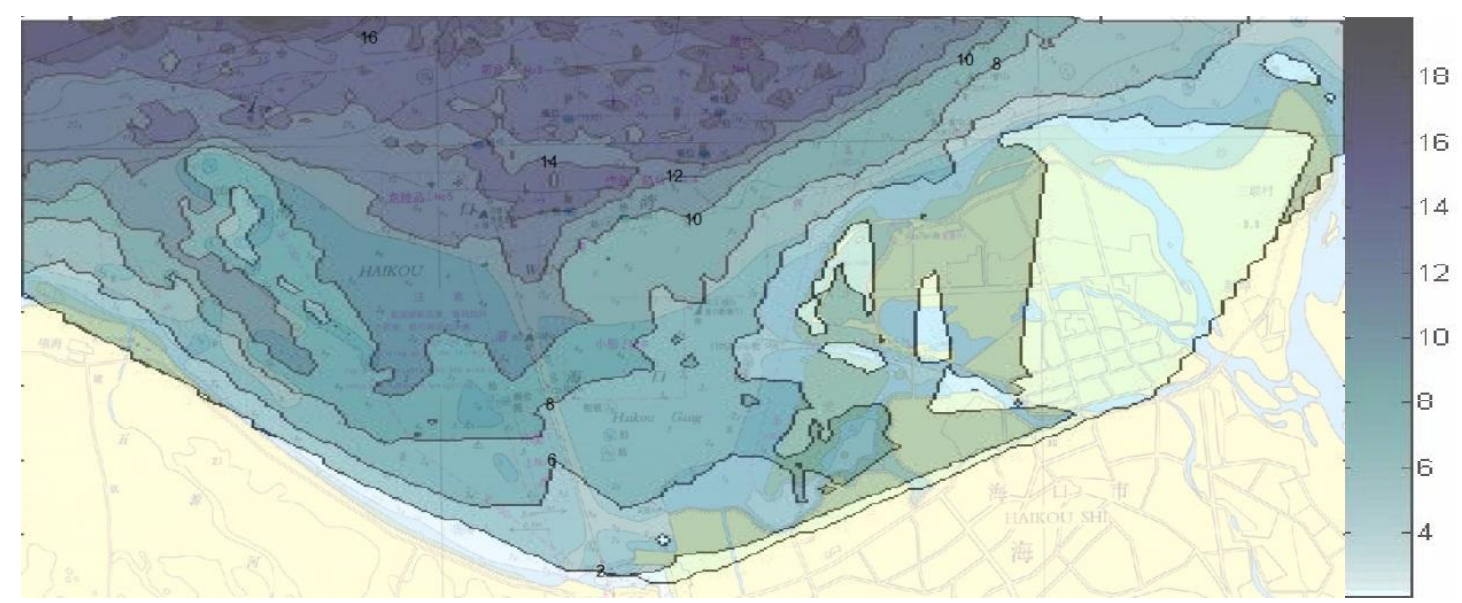

Fig. 3. The result of depth inversion with exponential equation of TM1/TM3

\section{CONCLUSION}

The spectral analysis of TM in Haikou Bay shows that TM3 has the best correlation with water depth in the single bands. And TM1/TM3 can increase the correlation with water depth than TM3.

The depth inversions with TM 3 and TM1/TM3 show that power exponential and exponential equations bring smaller error than linear and logarithmic equations. The error of depth inversion with exponential equation of TM1/TM3 is least, which can describe the main character of actual seabed. But the error is still considerable, so it is necessary to develop new depth inversion method.

\section{ACKNOWLEDGMENT}

The study has been supported by the National Natural Science Foundation (No.41076048 and No.40906044) and the Operation Expenses for Universities' Basic Scientific Research of Central Authorities (No.2011B05714).

\section{REFERENCES}

[1] Polcyn, F C, Sattinger,I J. Water depth determiantion using remote sensing techniques[A]. Proceedings of the 6th International Symposium on Remote Sensing of Environment, Ann Arbor, Michigan[C]. 1979:583-602.

[2] Polcyn, F C, Lyzenga, D R. Calculation of water depth from ERTS-MSS data [A]. Proceedings Symposium on Significant
Results Obtained from ERTS-1, New Carrollton, Maryland[C].1973:1433-1436.

[3] Tanis, F J, Hallada, W A. Evaluation of Landsat Thematic Mapper data for shallow water bathymetry [A]. Proceeding of 18th International Symposium on Remote Sensing of Environment, Ann Arbor, Michigan[C]. 1984:629-643.

[4] Tanis, F J, Byine, H J. Optimization of multispectral sensors for bathymetry applications[A]. Proceeding of 19th International Symposium on Remote Sensing of Environment, Ann Arbor, Michigan[C]. 1985:865-874.

[5] Lyzenga, D R. Shallow-water reflectance modeling with applications to remote sensing of ocean floor [A]. Proceeding of 13th International Symposium on Remote Sensing of Environment, Ann Arbor, Michigan[C]. 1979:583-602.

[6] Jerlov, N. G. Marine Optics[M]. Elsevier Scientific, Amsterdam.

[7] Polcyn, F. C., Sattinger, I. J. Water depth determination using remote sensing techniques[A]. In Proceedings of the Sixth International Symposium on Remote Sensing of Environment[C]. Ann Arbor, MI, 13-16 October, 1969, 10171028.

[8] Paredes, J. M., Spero, R. E. Water depth mapping from passive remote sensing data under a generalized ratio assumption[J]. Applied Optics, 1983(22):1134-1135. 